\title{
A techno-economic approach for capacity assessment and ranking of potential options for geological storage of $\mathrm{CO}_{2}$ in Austria
}

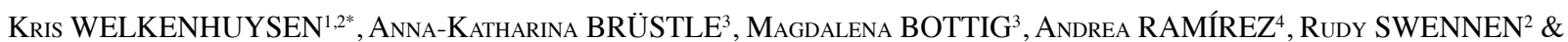 \\ KRIS PIESSENS ${ }^{1}$
}

${ }^{1}$ Royal Belgian Institute of Natural Sciences - Geological Survey of Belgium, Jennerstraat 13, 1000 Brussels, Belgium.

${ }^{2}$ Department of Earth and Environmental Sciences, KU Leuven, Celestijnenlaan 200E, 3001 Heverlee, Belgium. ${ }^{3}$ Geologische Bundesanstalt, Neulinggasse 38, 1030 Vienna, Austria.

${ }^{4}$ Copernicus Institute of Sustainable Development, Faculty of Geosciences, Utrecht University, Budapestlaan 6, 3584 CD Utrecht, The Netherlands.

* corresponding author: Kris.Welkenhuysen@naturalsciences.be

\begin{abstract}
Carbon dioxide capture and geological storage (CCS) is a means to drastically reduce greenhouse gas emissions. This paper shows an application to the Austrian context of a newly developed methodology for the assessment of geological reservoirs, based on expert opinions on the Schönkirchen Tief, Höflein, Schönkirchen Übertief, Reyersdorfer Dolomite, Aderklaa, AtzbachSchwanenstadt and Voitsdorf reservoirs. Because of a lack in reservoir-specific research for the storage of $\mathrm{CO}_{2}$, large uncertainties on the behaviour and use of the Austrian reservoirs exist. Therefore the potential of the reservoirs remains unknown. Geological, technological and economic simulations are performed which integrate different uncertainties. The results show that there is a significant potential for $\mathrm{CO}_{2}$ storage in Austria. The total practical and matched capacity for Austria is assessed at about 120 and $40 \mathrm{MtCO}$ respectively. An exploration priority ranking, based on reservoir development probability, shows that the Schönkirchen Übertief reservoir has the highest potential for storage and should be a primary target for further exploration.
\end{abstract}

KEYWORDS: Matched capacity, $\mathrm{CO}_{2}$ capture and storage, geological uncertainty.

\section{Introduction}

The global average concentration of $\mathrm{CO}_{2}$ in the atmosphere has risen from $280 \mathrm{ppmv}$ in pre-industrial times to almost 400 ppmv early 2014 (Keeling et al., 2014). Anthropogenic emission of greenhouse gasses $(\mathrm{GHG})$ such as $\mathrm{CO}_{2}$ from burning fossil fuels are a main contributor to this rise, causing global climate change (IPCC, 2014). $\mathrm{CO}_{2}$ capture and geological storage (CCS) is a potential means to significantly reduce emissions from large stationary industrial facilities (IPCC, 2005). $\mathrm{CO}_{2}$ is captured, purified, pressurized and transported to a suitable injection location. This location is determined by the presence of a suitable geological reservoir for safe and permanent storage. Possible reservoirs include depleted hydrocarbon fields, deep saline aquifers, man-made cavities and active hydrocarbon fields where $\mathrm{CO}_{2}$ is injected to enhance hydrocarbon production.

Several studies have indicated that storage capacity is available in Europe, although it is not evenly distributed (Christensen \& Holloway, 2004; Vangkilde-Pedersen et al., 2009). Long-distance and cross-border transport may therefore become inevitable (Neele et al., 2013). For countries with limited capacity, there are however a number of reasons to consider the development of domestic reservoirs instead of relying solely on export for $\mathrm{CO}_{2}$ storage. Apart from the possible strategic advantage, these reasons mainly come down to a potential lower transport and storage cost.

Scharf \& Clemens (2006) provided a first overview of potential storage reservoirs and accompanying capacity estimates for Austria. They estimate the total storage capacity for the country at $465 \mathrm{MtCO}_{2}$. This geological overview, however, does not consider geological uncertainties that influence capacity, nor do they consider the availability of $\mathrm{CO}_{2}$ sources and economic opportunities for $\mathrm{CO}_{2}$ capture, transport and storage trough space and time. It has been shown that there is an important interaction between these factors and reservoir capacity assessments for $\mathrm{CO}_{2}$ storage (Bachu et al., 2007; Keating et al., 2011; Middleton et al., 2012). As more information on a reservoir and its economic viability becomes available, its capacity estimate generally decreases. This has results in what is called the techno-economic resource pyramid for $\mathrm{CO}_{2}$ storage capacity. In its final step, a source-sink match determines which portion of the available reservoir space will actually be used for storage.

This paper aims to provide reservoir capacities and a ranking of the Austrian reservoirs as potential targets for $\mathrm{CO}_{2}$ storage considering a techno-economic framework. In order to obtain realistic results, uncertainties in data on capture, transport and storage are fully integrated in the analysis. In a first step, a geo-economic calculation scheme called "PSS (Policy Support System) Explorer" is used. This methodology relies on expert opinions for including reservoir uncertainties. Source-sink matching is done using the PSS III simulator (Piessens et al., 2012; Welkenhuysen et al., 2013). This methodology allows determination of the probability that a certain reservoir will be used, which reservoirs are primary targets for storage, and which capacity is available and will be used for storage. In this paper the emissions from two of the most $\mathrm{CO}_{2}$-intensive industries, the power and iron \& steel sector or about $30 \%$ of Austria's total emissions, will be simulated to be available for storage. With this research, a first realistic assessment is made on the economic potential of CCS and potential reservoirs in Austria, which can direct policy and provide targets for further investigation.

\section{Geology of Austria}

In Austria, the geological landscape is dominated by the mountain range of the Eastern Alps, the Penninic Units (the Flysch Zone and the tectonic windows), the Precambrian Bohemian Massif and the Cenozoic sedimentary basins (Fig. 1).

The Eastern Alps are subdivided into the Northern Calcareous Alps and the Central Alps with their boundaries along the Salzachtal-Ennstal-Mariazell-Puchberg (SEMP) fault to the north and the Periadriatic Lineament to the south. The Northern Calcareous Alps are built up of Permo-Mesozoic sediments deposited on the African passive continental margin. During the Cretaceous orogeny, these sediments together with their basal Palaeozoic sediments (the Grauwackenzone) were torn from their crystalline basement and thrusted to the north (Prey, 1980). The prevalent, mainly Palaeozoic aged crystalline rocks of the Central Alps represent the northern shelf of the African continent and tectonically underlie the Northern Calcareous Alps (Prey, 1980). Tectonic windows within the Central Alps, where mainly Penninic units come to surface due to uplift and erosion, are represented by the prominent Tauern window as well as the Unterengadiner, the Gargellen and the Rechnitzer windows (Prey, 1980), see Figure 1.

Along the northern side of the Calcareous Alps two main units (both mainly Cretaceous to Cenozoic deposits) are cropping out: the tectonically deeper Helvetic units, which represent 


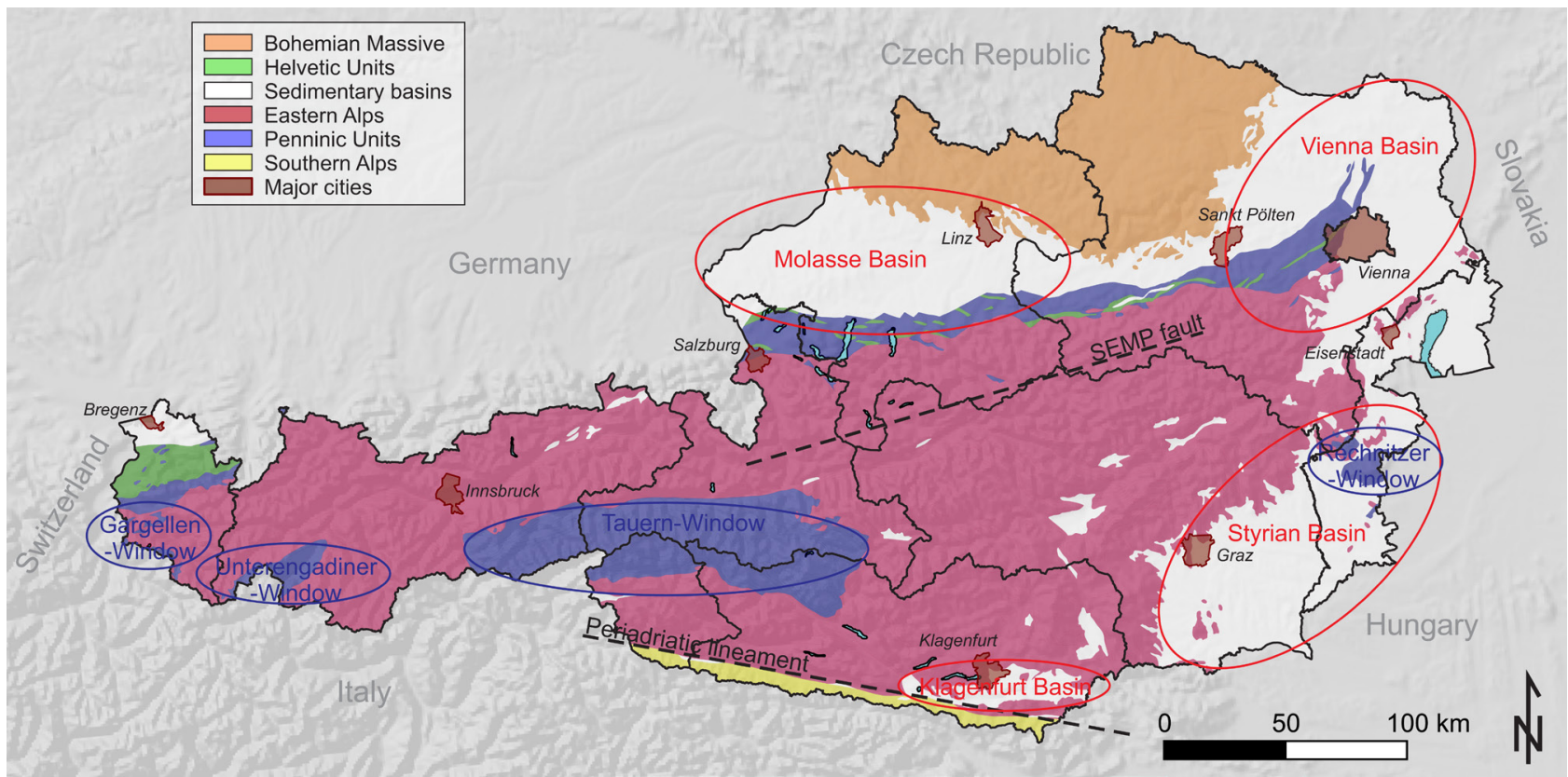

Figure 1. Map of the predominant geological structures in Austria. The main tectonic units, dominated by the mountain range of the Eastern Alps, are surrounded by different sedimentary basins. Hydrocarbon reservoirs are present in the Molasse and the Vienna Basins (Fig. 2).

European continental shelf deposits and the tectonically higher flysch nappes - Penninic deep water sediments (Wessely, 2006).

Cenozoic sedimentary basins are predominant alongside the main chain of the Alps to the North and East (Fig. 1). The largest basin, the Molasse Basin with its several kilometres thick Cenozoic marine to freshwater deposits, represents one of the country's main hydrocarbon reservoir systems. It was formed by flexural bending of the European craton plate underneath the advancing Alpine orogenic wedge to the south (Prey, 1980). The Eocene to Miocene Molasse sediments overly the Jurassic Cretaceous deposits of the European shelf which rest on top of the southwards subsiding crystalline basement namely the Bohemian Massif that crops out further to the north (Rupp, 2011).

The second largest sedimentary basin is the Vienna Basin which is bordered by the Eastern Alps to the West, the Carpathians to the Northeast and the Pannonian Basin to the East. It is influenced by the evolution of both of these orogenies and the formation of the Pannonian region. The basin evolution is characterized by the early Miocene piggy-back stage and the Middle to Late Miocene pull-apart stage at the sinistral Vienna Basin Transfer Fault (Seifert, 1992; Peresson \& Decker, 1997). The sinistral strike-slip "Leopoldsdorf Fault", with an overall vertical displacement of $4 \mathrm{~km}$, separates the deeply subsided and hydrocarbon-rich north-eastern part of the basin from the more shallow south-western part (Wessely, 2006).

The Styrian Basin is the third largest of the Cenozoic basins and is characterized by Miocene - Pleistocene volcanic activity. Eastward directed extension at the end of the Alpine orogeny was essential for the formation of the Styrian basin. These extensional tectonics are related to the lateral escape of the eastern Central Alps along major strike-slip fault zones to the east into the Pannonian region (Ebner \& Sachsenhofer 1991). Although there was extensive exploration for hydrocarbons in the Styrian Basin, no profitable reservoirs were found. As a side product of this exploration, the area was proven to have a geothermal potential.

\section{Potential reservoirs for $\mathrm{CO}_{2}$ geological storage}

Potential reservoirs for $\mathrm{CO}_{2}$ storage in Austria are known from former and ongoing exploitation of oil and gas fields. The fact that they contained crude oil or natural gas is a good indication for the leak tightness of the seal. Abandoned wells, however, pose additional risk as they may lead to leakage due to inappropriate abandonment practices. Other types of reservoirs,

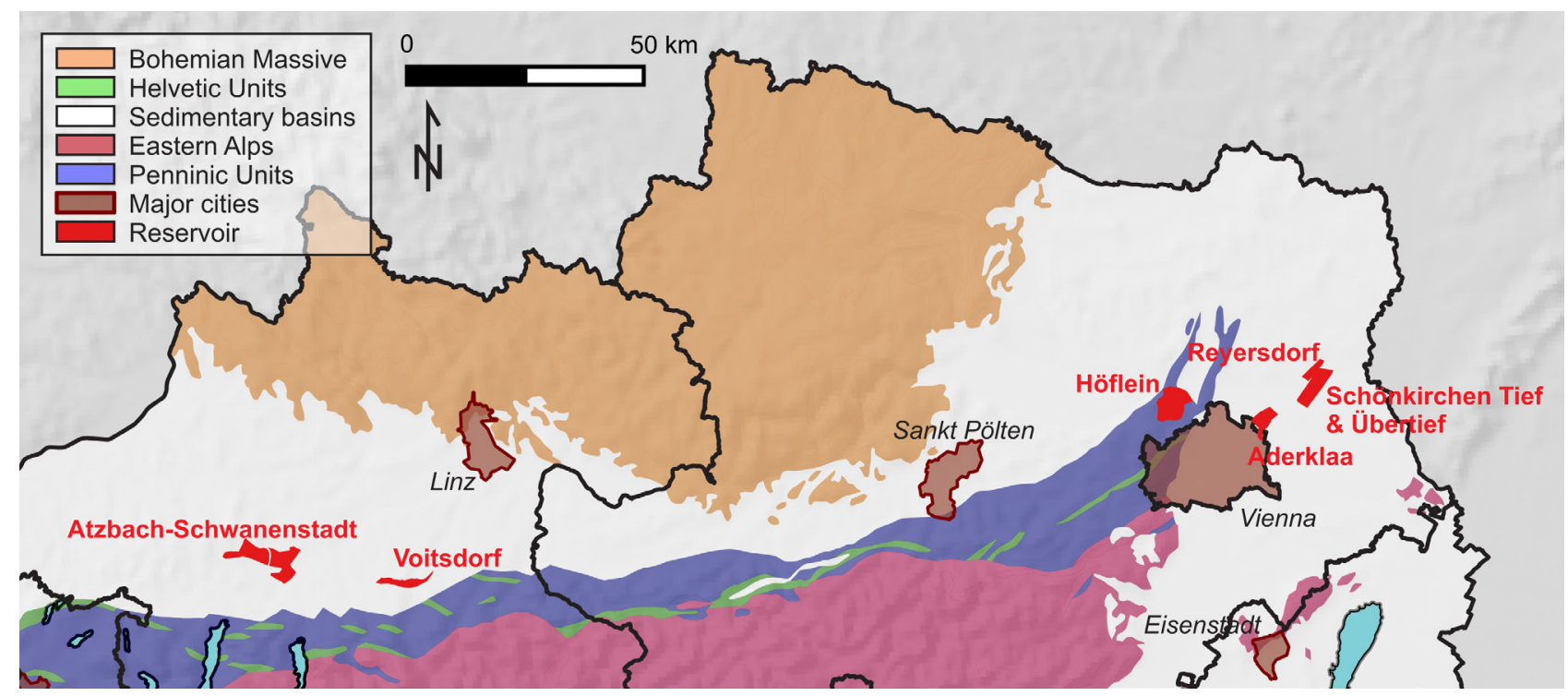

Figure 2. Location of the 7 hydrocarbon reservoirs (in red), considered by Sharf \& Clemens (2006) for $\mathrm{CO}_{2}$ storage, and used in this study. Reservoir contours are drawn after Brix \& Schultz (1993). 
such as aquifers, have not yet been identified, but it is possible that storage capacity is available. Seven candidate reservoirs for $\mathrm{CO}_{2}$ storage were identified by Scharf \& Clemens (2006), all located in the Cenozoic sedimentary basins in Upper and Lower Austria, and are commonly identified as the Schönkirchen Tief, Höflein, Schönkirchen Übertief, Reyersdorfer Dolomite, Aderklaa, Atzbach-Schwanenstadt and Voitsdorf (Fig. 2). The summary below is based on Scharf \& Clemens (2006).

The Schönkirchen Tief is a producing oil field, situated in the Vienna Basin in Lower Austria and operated by the Österreichische Mineralölverwaltung (OMV). Situated at 2800 $\mathrm{m}$ depth, this dolomite reservoir was first discovered in 1960 with an initial oil content estimated at $20 \mathrm{Mm}^{3}$. The Schönkirchen Tief is actually part of a hydrodynamic unit consisting of three connected reservoirs (Schönkirchen Tief, Schönkirchen Tief Gas and Prottes Tief). Because of the reservoir condition, structure and high permeability, this reservoir is probably a good candidate for $\mathrm{CO}_{2}$ storage. As the reservoir is exploited using relatively few wells, the risk of leakage along wells is lower. Scharf \& Clemens (2006) estimated the total capacity of the Schönkirchen Tief reservoir at $17 \mathrm{MtCO}_{2}$.

The Höflein reservoir in Lower Austria is operated by OMV. It is the second largest active gas reservoir in Austria, with an initial gas-in-place of 10 billion $\mathrm{m}^{3}$. It is a geological complex with multiple structural units at a depth of $2700 \mathrm{~m}$. Two-thirds of the gas is contained in dolomitic and quartzitic arenite, the rest in heterogeneous layers. This reservoir could be suitable for $\mathrm{CO}_{2}$ storage because of its large thickness and the homogeneity of the major part of the reservoir. The overlying layers, composed of pelitic sediments and tight limestones and marls, act as a seal. The initial gas in place contained $16 \%$ of $\mathrm{CO}_{2}$. The geochemistry of the reservoir and the sealing layer is already in equilibrium with this relatively high concentration of $\mathrm{CO}_{2}$, and the probability that the injection of $\mathrm{CO}_{2}$ will cause major alterations and eventually deterioration of the sealing properties of the overlying layer is low.

The Schönkirchen Übertief in Lower Austria is also operated by OMV. It is the largest sour gas reservoir in Austria, with an initial gas in place of 18 billion $\mathrm{m}^{3}$ and a $13 \% \mathrm{CO}_{2}$ content. This $5500 \mathrm{~m}$ deep reservoir has a thickness of $900 \mathrm{~m}$, and consists of fractured dolomite with a $6.5 \%$ porosity, and plattenkalk with a $2 \%$ porosity. Overall average permeability is $7 \mathrm{mD}$. $\mathrm{CO}_{2}$ storage capacity is estimated to be $22 \mathrm{Mt}$ (Scharf \& Clemens, 2006). Gas production is planned until 2019. This potential reservoir could be an ideal candidate for $\mathrm{CO}_{2}$ storage because the effect of $\mathrm{CO}_{2}$ on the reservoir and cap rock is known, there are no known connections to other aquifers, and all wells have been properly completed.

The Reyersdorf Dolomite in Lower Austria and operated by OMV, is a partly abandoned reservoir at a depth of ca. 2000 $\mathrm{m}$, with an oil rim and a big sour gas cap. This gas cap is still produced from one well. The end of gas production is expected by 2019 .

The Aderklaa reservoir in Lower Austria and operated by $\mathrm{OMV}$, is an abandoned gas reservoir with an initial gas in place of 4 billion $\mathrm{m}^{3}$. This Triassic dolomite reservoir has an average thickness of $100 \mathrm{~m}$ and an average porosity of $7.7 \%$.

The Atzbach-Schwanenstadt reservoir in Upper Austria and operated by Rohöl-Aufsuchungs AG (RAG), consists of several gas-bearing formations, with an initial gas in place of 4.4 billion $\mathrm{m}^{3}$. The net thickness is $9 \mathrm{~m}$ with an average permeability of 25 $\mathrm{mD}$, at a depth of up to $1600 \mathrm{~m}$. The estimated storage capacity by Scharf \& Clemens (2006) is $13 \mathrm{MtCO}_{2}$. Polak \& Grimstad (2009) estimated the total storage capacity at $14.5 \mathrm{MtCO}_{2}$, based on the produced amount of natural gas.

The Voitsdorf oil field in Upper Austria and operated by RAG, consists of an Eocene and a Cenomanian reservoir, with depths around $1600 \mathrm{~m}$. This potential reservoir is not connected to an aquifer. Storage capacity of both parts combined is $6 \mathrm{MtCO}_{2}$ (Scharf \& Clemens, 2006).
All of the suitable considered reservoirs are situated in the proximity of industrialized areas. The total theoretical capacity is estimated at $465 \mathrm{MtCO}_{2}$ by Scharf \& Clemens (2006). Some of the fields could become accessible for $\mathrm{CO}_{2}$ storage within a short period of time, due to their projected end of production. There might also be possibilities to apply $\mathrm{CO}_{2}$-enhanced oil or gas recovery (EOR/EGR) to active reservoirs. This option is, however, not taken into account in the current study.

Storage in deep saline aquifers may be feasible, but identification of potential storage locations is not possible based on current geological knowledge and legal constraints. These are therefore excluded from the current evaluation. Storage schemes associated with salt deposits have also been proposed (IPCC, 2005), but neither salt domes nor mined cavities in Austria are considered suitable because the salt deposits do not have an appropriate extension and/or are not stable (Sharf \& Clemens, 2006).

\section{Methodology}

To assess the potential of a reservoir to be used in a CCS project, both the available capacity and its economic viability as part of the integrated CCS project should be assessed. Bachu et al. (2007) developed a potential $\mathrm{CO}_{2}$ reservoir ranking based on the exploration and knowledge level which is currently being used in many assessments of $\mathrm{CO}_{2}$ storage capacity (e.g. Vangkilde-Pedersen et al., 2009; Halland et al., 2014). The ranking uses four categories: theoretical, effective, practical and matched. General assessments of reservoirs based on little data are classified as theoretical capacity. Using geological exploration data and applying general practical and economic thresholds, first an effective and then a practical capacity, or available capacity, can be estimated. The matched capacity is the fraction of the practical capacity that will actually be used for storage. Assessing the practical capacity generally requires large investments in exploration, while the matched capacity will only be known at the time of operation. From this concept, one would expect the theoretical capacity to be the largest number, and the matched capacity the smallest. Our results however show that the average matched capacity numbers can be larger than the average practical capacity numbers, which seems contradictory. Further clarification will be provided in the discussion of the results.

A methodology for $\mathrm{CO}_{2}$ storage reservoir assessment, that uses the classification principle by Bachu et al. (2007), was presented in a previous study (Welkenhuysen et al., 2013) and applied to reservoirs in Belgium. This methodology was specifically developed for the assessment of reservoirs with a large variety in uncertainty ranges, and it enables making a realistic assessment of the practical and matched capacity of these reservoirs. It is based on the geo-economic evaluation of potential reservoirs with a calculation scheme called "PSS Explorer", and a sourcesink matching by a geo-techno-economic simulator called "PSS III". A brief overview of the methodology and how it is applied in this paper is given hereafter.

Input data on potential reservoir systems are not provided in the classical form of reservoir parameters such as porosity and permeability. Instead, experts with good knowledge on $\mathrm{CO}_{2}$ storage in general and more specific on the reservoirs in question are asked to provide their judgements. These experts first have to decide individually if they have sufficient knowledge to make such judgements on the individual reservoirs. The reservoir concept is reduced to only the three most basic characteristics: total capacity, injectivity (yearly capacity) and probability of reservoir failure (reservoir fundamentally unsuited for storage of $\mathrm{CO}_{2}$ because of for example fractures in seal). The experts are asked to provide their judgements for a fixed set of potential reservoirs under the form of probability density functions (PDF) for capacity and injectivity, and a percentage for the probability on reservoir failure. Further details of this methodology are explained in Welkenhuysen et al. (2013). 
The rationale behind using expert judgements instead of traditional data is that they provide data that includes the whole geo-technical uncertainty range, which is necessary for the further economic assessments. Concrete data for $\mathrm{CO}_{2}$ storage is in many cases not available, and most information is confidential and in hands of hydrocarbon companies. The validity and problems using expert input are discussed in Welkenhuysen et al. (2013). A number of Austrian experts were selected and approached, based on their knowledge and experience with Austrian geology, reservoir engineering, $\mathrm{CO}_{2}$ storage and their knowledge of the individual reservoirs. Three experts were willing to provide estimates for the selected reservoirs. In Figure 9 all expert input data are shown. As all potential reservoirs that are considered here are or were active hydrocarbon reservoirs, and are therefore sufficiently explored, the expert capacity assessments are considered to be at the effective capacity level. All experts are Austrian geoscientists with experience in reservoir geology and have a good knowledge of the reservoirs they chose to evaluate. It was agreed that their input would be anonymous.

Experts do not necessarily agree on the reservoir properties. It is therefore very important to follow the methodology for gathering expert input as described in Welkenhuysen et al. (2013). Experts have to be addresses individually, because it is shown that a consensus following discussion does not, in contrast to general belief, necessarily provide a more accurate or reliable view (Morgan \& Keith, 2008). As an expert, a person probably has his reasons to have a different opinion. When compiling the expert input, all experts were given equal weight (i.e. the opinions of all experts are equally credible). When experts do not agree regarding the probabilistic distribution, this will result in bi-(or more)-modal distributions. For the failure probability (single number input), the average of all experts is taken. This average equals the result of a random sampling of their individual input, if all experts are given equal weight. The outcome of this methodology reflects the true uncertainties of the state of knowledge on these reservoirs.

To assess the practical reservoir capacity, the practical and economic viability of reservoir development is calculated with the geo-economic PSS Explorer calculation scheme. The expert judgements serve as input for a Monte Carlo analysis of an economic decision scheme for reservoir exploration and development. The result is a set of probability density functions (PDF) of each reservoir for total capacity and injectivity in function of the price a potential capture facility is willing to pay for storage (storage budget) varying between 1 and $30 € / \mathrm{tCO}_{2}$, which is the expected range of storage costs (ZEP, 2011). The result of this PSS Explorer calculation is the practical capacity assessment. The average practical capacity that is given in the results section is generally the capacity function at $15 € / \mathrm{tCO}_{2}$, because at this relatively high price point all reservoirs are considered to be explored for $\mathrm{CO}_{2}$ storage.

The probability density functions for reservoir capacity and injectivity are direct input parameters for the PSS III simulator. PSS III is a bottom-up techno-economic simulator for source-sink matching in a sector-wide economy (energy or other). Investment decisions are taken based on risk and return of individual projects that can use conventional, CCS or renewable production technology. A CCS project consists of a production facility with $\mathrm{CO}_{2}$ capture, pipeline transport and final storage in a geological reservoir. Technological (e.g. capture costs and performance), economic (e.g. $\mathrm{CO}_{2}$ emission price) and geological (e.g. reservoir capacity) uncertainty is handled with stochastic parameters in a nested Monte Carlo approach for limited foresight. Because the value of the stochastic parameters changes in every Monte Carlo iteration, the resulting investment decisions and their consequences change as well. In practice, a yearly evaluation of the balance between production and demand is made for a certain sector in a certain region or country. In case additional production is needed, because of an increase of demand or the shut-down of existing facilities, the available investment options are evaluated and a realistic investment decision is taken based on two main economic principles: Real Options Analysis (Dixit \& Pindyck, 1994) and Optimal Portfolio Theory (Markowitz, 1987).

The results provide an indication of the chance that a reservoir will be developed in the future (development probability), and an assessment of the exploited storage capacity when the reservoir is used in CCS projects (total and yearly matched capacity) for the chosen timeframe. Not every reservoir will be used for storage in every Monte Carlo iteration. The matched capacity is therefore described by two parameters: the development probability, and the probability distribution of (non-zero) matched capacities, i.e. the capacity that is used in case a project is activated.

\section{Techno-economic scenario constraints}

The European Union (EU-15) has committed to reduce its GHG emissions by $8 \%$ in the $2008-2012$ period in comparison to the reference year (1990 generally and also for Austria) under the UNFCCC Kyoto protocol (European Council, 1993). After the Kyoto protocol came into effect in 2005, Austria committed to a target of $13 \%$ reduction (UNFCCC, 2006). Furthermore, a European effort-sharing concept deals with a reduction of GHG emissions of $20 \%$ by 2020 (in comparison with 1990 emissions) or a reduction of $16 \%$ for Austria (European Parliament, 2009). However, reported emissions for 2012 have shown an increase of about $2.5 \%$ of GHG emissions compared to 1990 (Umweltbundesamt Österreich, 2014a). In 1990, Austria's GHG emissions were $78 \mathrm{MtCO}_{2}$ equivalent $\left(\mathrm{CO}_{2} \mathrm{e}\right)$; in 2012 they were over $80 \mathrm{MtCO}_{2} \mathrm{e}$ (Fig. 3), excluding land use, land use change and forestry (LULUCF). $\mathrm{CO}_{2}$ is the main GHG with an $85 \%$ share in 2012 , of which $99 \%$ comes from the combustion of fossil fuels. These emission numbers indicate that additional measures are necessary to reach climate goals.

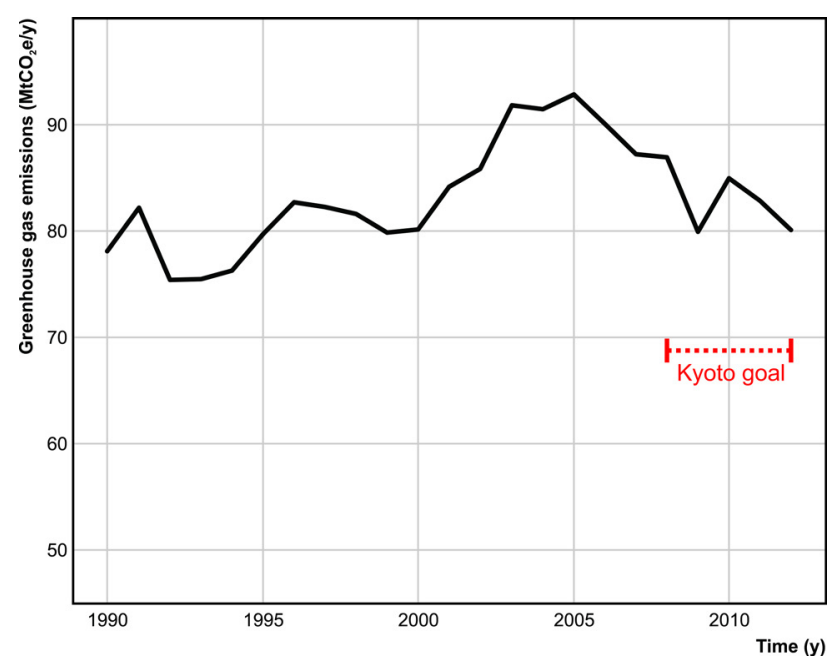

Figure 3. Austrian greenhouse gas emissions since 1990, the Kyoto Protocol reference year. Despite a decrease since 2005, emissions show an increase of $2.5 \%$, opposed to a Kyoto goal of a $13 \%$ reduction (Umweltbundesamt Österreich, 2014a).

According to the IEA (2014), CCS is expected to contribute $14 \%$ to the $\mathrm{EU} \mathrm{CO}_{2}$ emission reduction in 2050 to have at least a $50 \%$ chance to limit global warming to $2{ }^{\circ} \mathrm{C}$ (2DS target) in the most cost-effective manner, compared to the 6DS scenario (continuation of current trends and policies). Public opinion in Austria is in general negative towards geological storage of $\mathrm{CO}_{2}$, and CCS does not form part of Austria's current climate policy or future strategy. In fact, industrial scale geological storage of $\mathrm{CO}_{2}$ is forbidden until at least 2018, when its status will be re-evaluated (Umweltbundesamt Österreich, 2014b). The main arguments against storage are the level of technology maturity and the possible risks related to storage.

Two of the main $\mathrm{CO}_{2}$ emitting sectors in Austria, electricity and iron \& steel production, were simulated. Emissions from electricity (6.2 $\left.\mathrm{MtCO}_{2} / \mathrm{y}\right)$ and iron \& steel (11.3 $\left.\mathrm{MtCO}_{2} / \mathrm{y}\right)$ production amount to $26 \%$ of the total $\mathrm{CO}_{2}$ emissions of Austria (68 $\mathrm{MtCO}_{2} / \mathrm{y}$, including industry, domestic and transport, 
excluding land use, land use change and forestry; reporting year 2012) (E-PRTR, 2015; Umweltbundesamt Österreich, 2014a). Simulations are performed starting in 2013 (actual year of simulation) until 2050, which is considered to be the period of commercial introduction of CCS technology.

Simulations in PSS III are made in a framework that defines certain boundaries, called scenarios. The main scenario parameters are the $\mathrm{CO}_{2}$ emission price (i.e. the cost for emitting one tonne of $\mathrm{CO}_{2}$ into the atmosphere, the European Emission Allowance price equivalent under the Emission Trading System, EU ETS), sectoral demand and fuel prices. The scenario that was used for the current simulations considers a long-term economic growth and a renewed interest in climate mitigation policy. Considering historical data of the past decade, a longterm 1\% demand increase for electricity is used (Statistics Austria, 2009). The same $1 \%$ growth is assumed for the iron $\&$ steel sector activity, as a result of general economic growth. We assume that a clear climate policy will result in a rising $\mathrm{CO}_{2}$ emission price, with at first a gradual rise; a faster rise once all mechanisms are implemented, and a stabilisation at $100 € / \mathrm{tCO}_{2}$ in 2050 (Fig. 4, Table 1). This is a scenario which corresponds well with the projections of the European Commission (2013). Next to the large database of production technologies already available in PSS II (Piessens et al., 2012), technologies for the use of renewable sources of energy for the power sector have been added. Cost and performance data on wind, photovoltaic solar, concentrated solar and small-to-medium hydroelectricity production was gathered from the IEA-ETSAP network report (IEA-ETSAP, 2013).

It was assumed that the existing (large) hydroelectric dams are not decommissioned within the simulation timeframe. Because of physical and economic restrictions to the installation of renewable energy production, an upper limit was imposed on biomass, solar, hydro and wind electricity production, based on the maximum realisable potential for 2020, as reported by the Austrian Federal Ministry of Agriculture, Forestry, Environment

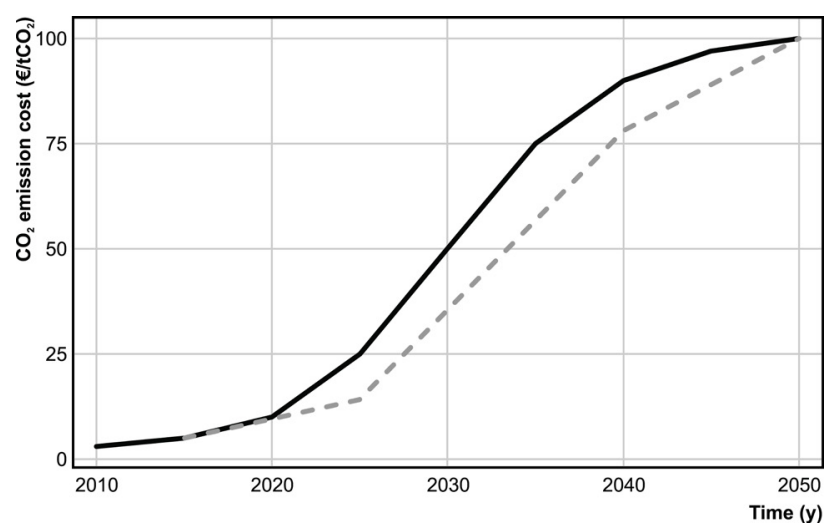

Figure 4. $\mathrm{CO}_{2}$ price scenario used for the PSS III simulations (black line). This scenario aligns well with predictions used by the European Commission (2013) (dashed grey line). and Water Management (BMLFUW, 2009). No information after 2020 is available and significant changes in technological development, economics and land use can occur over time. These upper limits were therefore increased with a factor 2 for 2050 as a rough approximation (Table 1). Although not much public information is available, it was assumed that the geological reservoirs would become available in 2020. Note that this timing is compatible with at least two of the active fields which are expected to cease operation in 2019 .

\section{Results and discussion}

The PSS Explorer calculation scheme carried out 50000 MonteCarlo iterations to produce practical capacity and probability numbers. 461 Monte-Carlo iterations, which equals to about two weeks of intensive 18-thread parallel computing, were run with the PSS III simulator for the power and iron and steel sectors. The practical (PSS Explorer) and matched (PSS III simulator) capacity results are displayed in Figure 10 and Table 2. These results are presented as probability density functions. In the text, probabilistic results are given as a mean, and the 5 and 95 percentile values (P5 and P95) as given by the Monte-Carlo calculation results. The development probability is calculated as the fraction of the 461 Monte-Carlo iterations in which a reservoir is active in a CCS project.

The results indicate that the average total practical capacity of Austria, as calculated by PSS Explorer, is $118 \mathrm{MtCO}_{2}$ (P5: $47 \mathrm{Mt}$, P95: $215 \mathrm{Mt}$ ). The average matched capacity for the whole country for the calculated scenario is estimated at $39 \mathrm{MtCO}_{2}$ (P5: $5 \mathrm{Mt}$; P95: $130 \mathrm{Mt}$ ). Comparing the theoretical capacity number from Scharf \& Clemens (2006) of $465 \mathrm{MtCO}_{2}$, with these numbers, they comply with the techno-economic resourcereserve classification by Bachu et al. (2007). In almost every Monte-Carlo iteration of PSS III some amount of $\mathrm{CO}_{2}$ was stored in an Austrian reservoir, for the current scenario the probability that one or more reservoirs are used for CCS in Austria between 2010 and 2050 is $97 \%$.

Most individual reservoir development probabilities lie between 20 and $30 \%$ and average total matched capacity numbers range between 7 and $40 \mathrm{MtCO}_{2}$ (Table 2). The Schönkirchen Übertief appears as most favourable for development probability (31\%), average total (40 $\mathrm{MtCO}_{2}$; P5: $4 \mathrm{Mt}$; P95: $\left.150 \mathrm{Mt}\right)$ and yearly matched capacity $\left(2.3 \mathrm{MtCO}_{2}\right.$; P5: $0.4 \mathrm{Mt}$; P95: $\left.8.8 \mathrm{Mt}\right)$. The least favourable reservoir is the Reyersdorf dolomite, with only $5 \%$ development probability and a total matched capacity of $13 \mathrm{MtCO}_{2}$. The Atzbach-Schwanenstadt is estimated to have the smallest matched capacity ( $7 \mathrm{MtCO}_{2}$; P5: $1 \mathrm{Mt}$; P95: $18 \mathrm{Mt}$ ). Individual matched capacity ranges between 7 and $40 \mathrm{MtCO}_{2}$, while the total national capacity is only $39 \mathrm{MtCO}_{2}$. This apparent contradiction appears because not every reservoir is developed in every Monte Carlo iteration. Development probability and capacity numbers should always be considered together (e.g. 40 $\mathrm{MtCO}_{2}$ and $31 \%$ for the Schönkirchen Übertief, and $39 \mathrm{MtCO}_{2}$ and $97 \%$ for the whole of Austria). In Figures 5 and 6 the total

\begin{tabular}{|c|c|c|c|c|c|c|c|}
\hline $\begin{array}{l}\text { Time } \\
\text { (y) }\end{array}$ & $\begin{array}{r}\text { Solar } \\
(\text { GWh }) \\
\end{array}$ & $\begin{array}{r}\text { Hydro } \\
(\text { GWh) }\end{array}$ & $\begin{array}{l}\text { Wind } \\
(\mathbf{G W h})\end{array}$ & $\begin{array}{l}\text { Biomass } \\
(\text { GWh })\end{array}$ & $\begin{array}{c}\text { Demand Power } \\
\text { (GWh) }\end{array}$ & $\begin{array}{c}\text { Demand Iron \& Steel } \\
(\mathrm{kt})\end{array}$ & $\begin{array}{l}\mathrm{CO}_{2} \text { price } \\
\left(€ / \mathrm{tCO}_{2}\right)\end{array}$ \\
\hline 2010 & 10000 & 7000 & 6000 & 6000 & 65656 & 7272 & 3 \\
\hline 2015 & & & & & & & 5 \\
\hline 2020 & 10000 & 7000 & 6000 & 6000 & 72386 & 8025 & 10 \\
\hline 2025 & & & & & & & 25 \\
\hline 2030 & & & & & 79806 & 8847 & 50 \\
\hline 2035 & & & & & & & 75 \\
\hline 2040 & & & & & 87986 & 9754 & 90 \\
\hline 2045 & & & & & & & 97 \\
\hline 2050 & 20000 & 14000 & 12000 & 12000 & 97004 & 10754 & 100 \\
\hline
\end{tabular}

Table 1. Most important scenario data used for the PSS III simulations. From left to right: the upper limits of renewable energy production for solar, hydro, wind and biomass power production; the country-wide demand for electrical power and iron \& steel; and the $\mathrm{CO}_{2}$ emission cost. Blank spaces are interpolated by PSS III. 


\begin{tabular}{lcccccc}
\hline Reservoir & $\begin{array}{c}\text { Theoretical } \\
\text { capacity from } \\
\text { literature (Mt) }\end{array}$ & $\begin{array}{c}\text { Practical } \\
\text { capacity total } \\
\text { (X (P5; P95) Mt) }\end{array}$ & $\begin{array}{c}\text { Practical } \\
\text { capacity yearly } \\
\text { (X (P5; P95) Mt) }\end{array}$ & $\begin{array}{c}\text { Matched } \\
\text { capacity total } \\
\text { (X (P5; P95) Mt) }\end{array}$ & $\begin{array}{c}\text { Matched } \\
\text { capacity yearly } \\
\text { (X (P5; P95) Mt) }\end{array}$ & $\begin{array}{c}\text { Counts } \\
\text { Development } \\
\text { probability } \\
\text { (\%) }\end{array}$ \\
\hline Schönkirchen Tief & $16-17$ & $20(5 ; 55)$ & $0.8(0.2 ; 1.7)$ & $20(3 ; 62)$ & $1.5(0.4 ; 4.6)$ & 112 \\
Höflein & & $18(5 ; 40)$ & $0.7(0.2 ; 1.5)$ & $15(4 ; 34)$ & $1.0(0.4 ; 3.4)$ \\
Schönkirchen Übertief & 22 & $31(7 ; 105)$ & $1.2(0.4 ; 3.3)$ & $40(4 ; 150)$ & $2.3(0.4 ; 8.8)$ & 121 \\
Reyersdorf Dolomite & & $6(1 ; 18)$ & $0.3(0 ; 0.8)$ & $13(1 ; 24)$ & $1.0(0.4 ; 1.4)$ & 21 \\
Aderklaa & & $23(1 ; 61)$ & $0.8(0 ; 2.5)$ & $25(5 ; 76)$ & $1.7(0.4 ; 5.2)$ & 99 \\
Atzbach-Schwanenstact & 13.44 & $13(8 ; 15)$ & $0.6(0.4 ; 0.7)$ & $7(1 ; 18)$ & $0.8(0.3 ; 1.5)$ & 86 \\
Voitsdorf & 6.1 & $31(4 ; 91)$ & $0.8(0.2 ; 3)$ & $33(5 ; 101)$ & $1.7(0.4 ; 5.2)$ & 130 \\
\hline Austria & 465 & $118(47 ; 215)$ & $4.3(2 ; 7.6)$ & $39(5 ; 130)$ & $2.5(0.4 ; 9.3)$ & 445 \\
\hline
\end{tabular}

Table 2. Summarized PSS III simulation results for the Austrian reservoirs, and Austria as a whole. The practical capacity numbers, calculated by PSS Explorer, and the matched capacity as a result of source-sink matching by PSS III, are compared to the theoretical capacity numbers stated in literature. The development probability results from the division of the number of Monte Carlo calculations in which a certain reservoir is used, divided by the total number of calculations (461).

and yearly matched and practical capacity assessments are shown as boxplots, and compared to the theoretical capacities as stated in literature.

The capacities found in this paper are slightly higher than those reported by Scharf \& Clemens (2006), as can be seen in Table 2. In both cases however the Schönkirchen Übertief reservoir is the largest reservoir. Only for the Voitsdorf reservoir, our calculations show a significant larger capacity ( 5 times larger than published numbers). For this reservoir, individual expert judgements do not only differ but also mostly do not overlap. Consequently, this is also the reservoir with the largest uncertainty ranges in the PSS III output. The Voitsdorf and Atzbach-Swanenstadt reservoirs were also assessed by only 2 of the 3 experts, which could reduce the quality of the final assessment. However, both the average results and the uncertainty ranges show no abnormal variation, which suggests there is no significant difference in quality. Note that the practical capacity PDFs (Fig. 10) are similar in shape compared to the expert judgements graphs (Fig. 9). This means that, at least for this study, the capacity that is assigned by the experts is also available at practical capacity level.

For most reservoirs, the average matched capacity is also close to the average practical capacity at $15 € / \mathrm{tCO}_{2}$ (dashed line in Fig. 10). For four of the seven reservoirs, the average matched capacity is even slightly larger. The matched capacity results are in essence a subsampling of the practical capacity PDFs at different storage budgets. The overall average storage cost in the source-sink matching (for the matched capacity) is just over a relatively high $13 € / \mathrm{tCO}_{2}$. This is close to the $15 € / \mathrm{tCO}_{2}$ storage budget of which the practical capacity results are displayed, and therefore a correct comparison between both can be made. As the averages of practical and matched capacity are close for all reservoirs, the subsampling - i.e. CCS deployment - occurs on average without preference for particular high or low capacity numbers.

When comparing the practical and matched capacity PDF's in more detail (Fig. 10), a preferential sampling can, however, be observed. There are clear peaks present in the matched capacity PDFs, which relate to the discrete amount of $\mathrm{CO}_{2}$ produced by an industrial facility. This explains why in some cases the average matched capacity is higher than the practical: if only very limited practical capacity is available, there will be no source-sink match. Monte Carlo calculations where no source-sink match is made, and thus no storage project is activated, are not considered when calculating the average of the matched capacity. Therefore these zero values only influence the development probability and not the average matched capacity. A project will only be activated in the case that the random sampling is at the higher end of the practical capacity range, which typically causes the average matched capacity to be higher than the practical capacity. The cause of this observation is the splitting of the development probability and the stochastic (non-zero) matched capacity, which is done because this is more intuitive and facilitates indepth interpretation. If such a split would not be made, then the matched capacity would always be smaller than the practical capacity. This also demonstrates the importance of distinguishing between matched and practical capacity.

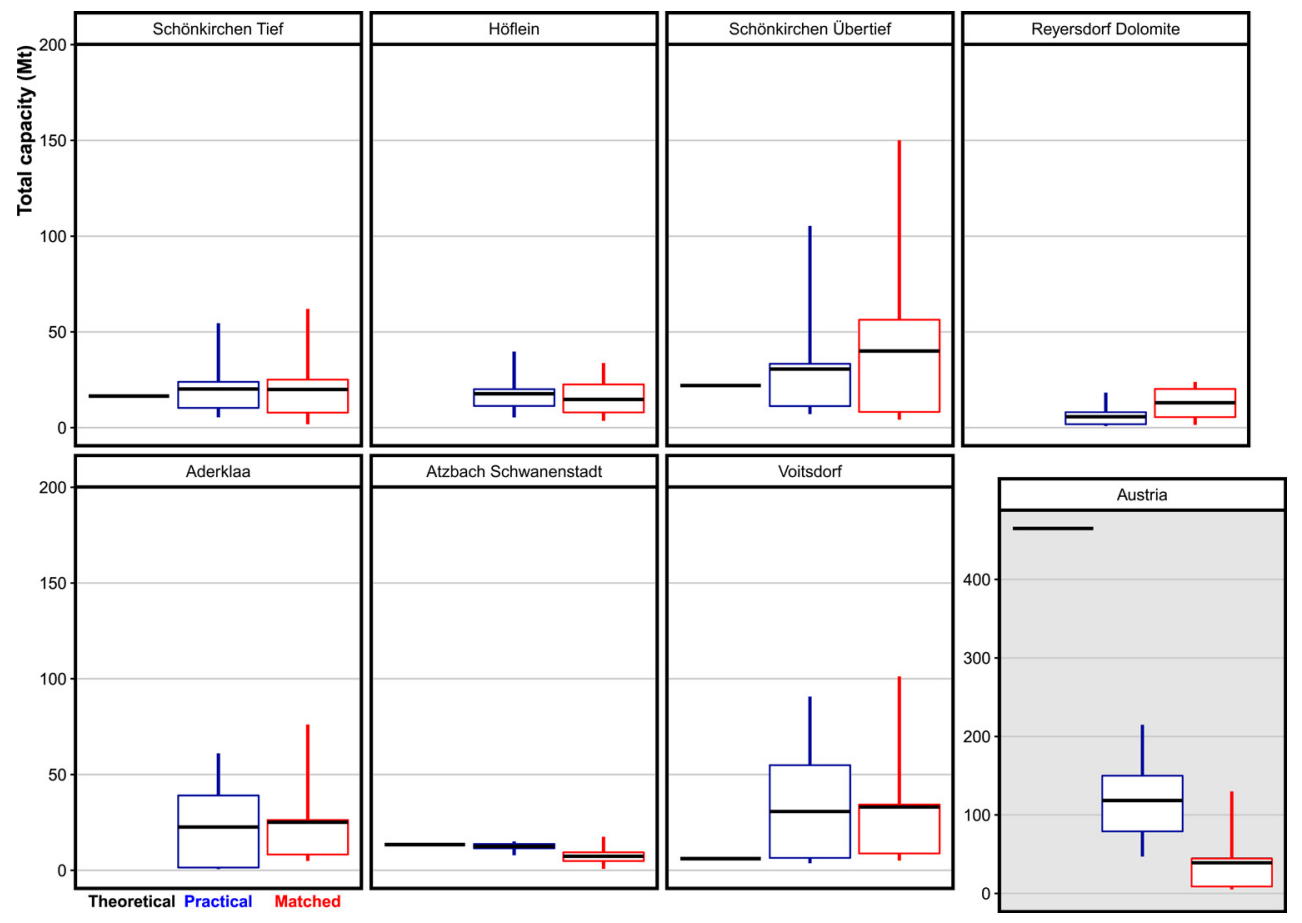

Figure 5. Boxplots for the comparison of the total theoretical capacity from literature with the practical and matched capacity assessments from PSS III. The black line indicates the average, the box covers the 25th-75th percentile. The whiskers show the 5th-95th percentile as stated in Table 2. 
Figure 6. Boxplots of the yearly practical and matched capacity assessments from PSS III. No yearly theoretical capacity assessments are available for comparison. The black line indicates the average, the box covers the 25th-75th percentile. The whiskers show the 5th-95th percentile as stated in Table 2 .

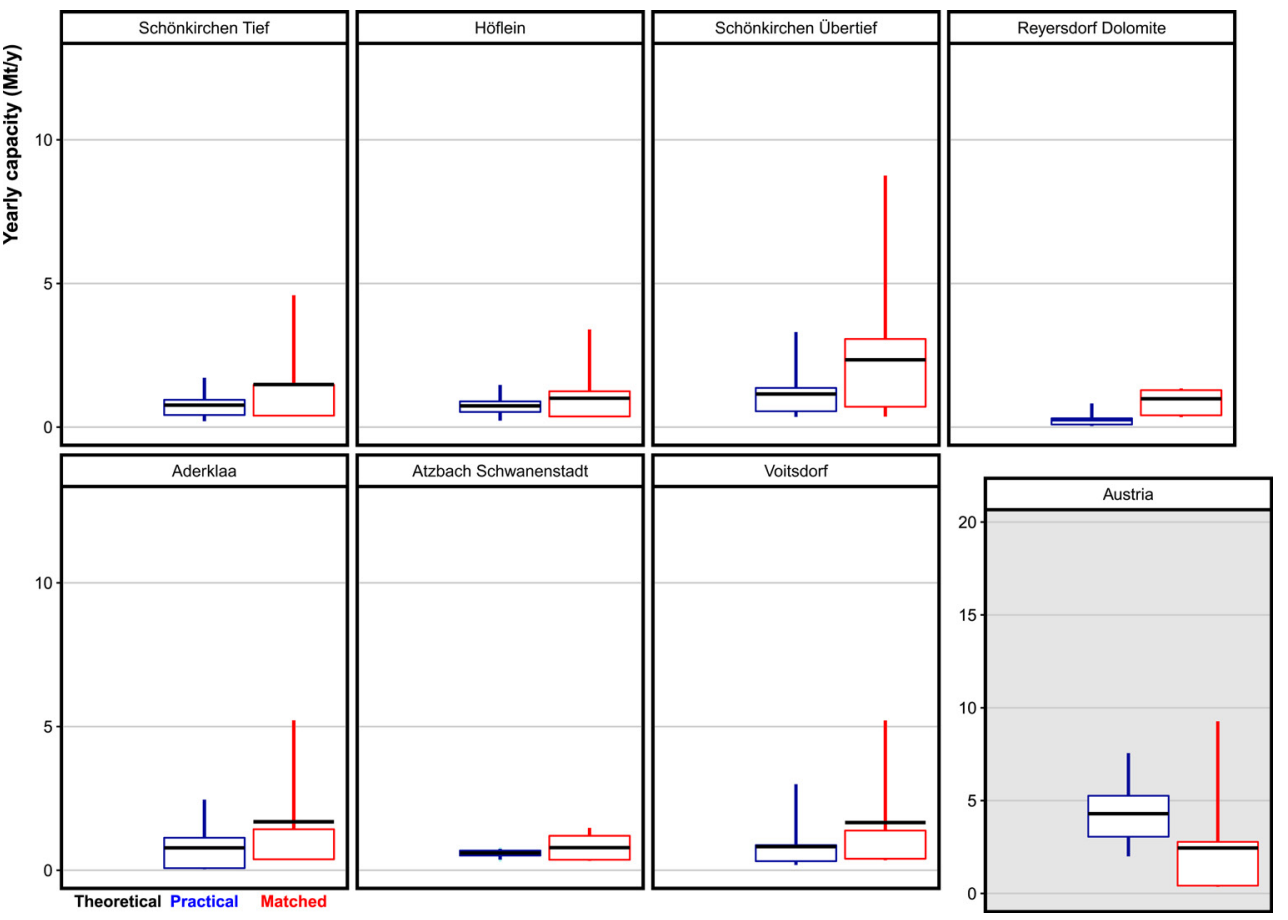

The reservoirs can be ranked by their development probability, which results in an exploration priority list (Fig. 7). Higher ranked reservoirs have a higher chance on being matched to a $\mathrm{CO}_{2}$ source, and could be considered as primary targets in future exploration. The Schönkirchen Übertief, Voitsdorf and Höflein reservoirs are ranked the highest with development probabilities over $25 \%$, followed by the Schönkirchen Tief, Aderklaa and Atzbach-Schwanenstadt reservoir. The Reyersdorf Dolomite reservoir is ranked the lowest. According to these results, the Schönkirchen Übertief could be a primary target for further research at this stage. There is also some degree of correlation between capacity and development probability, as the highest ranked reservoirs (Schönkirchen Übertief and Voitsdorf) have the highest practical and matched capacities.

The findings of this research point out a relatively low storage capacity and high storage cost. This indicates that there are important limiting factors to the actual development of $\mathrm{CO}_{2}$ storage reservoirs. Two main bottlenecks for the geological storage of $\mathrm{CO}_{2}$ in Austria can be identified.

First is the limited practical capacity of individual reservoirs. The average total and yearly capacities are low compared to the $\mathrm{CO}_{2}$ emissions of a full-size, $1 \mathrm{GW}$ coal-fired power plant $\left(\sim 5 \mathrm{MtCO}_{2} / \mathrm{y}\right)$. It is, however, important to consider the whole uncertainty range of these practical and matched

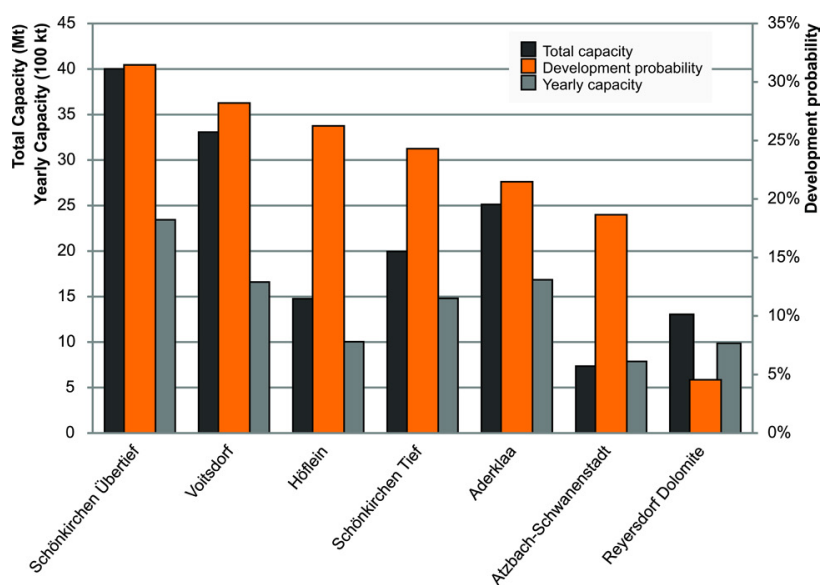

Figure 7. Reservoir exploration priority ranking, based on the development probability (orange). Total (dark grey, in $\mathrm{Mt}$ ) and yearly (light grey, in $100 \mathrm{kt}$ ) capacities are also given. The Schönkirchen Übertief is the most favourable, while the Reyersdorf Dolomite seems not favourable. capacity simulations, instead of only the average. Higher-thanaverage capacities have a significant probability as well, which would enable such a large-scale CCS project. The simulation methodology might also be limiting the installation of large capture plants: in the model a source can only be linked to one reservoir at the same time, which automatically eliminates smaller reservoirs in the source-sink matching process. Simulation results also show a significant possibility that after the commercial introduction of CCS, domestic reservoir capacity can be filled up rapidly. Figure 8 shows the probability that the reservoirs are filled up completely by a certain moment in time. Already before 2025 there is a small probability that some reservoirs reach their maximum capacity. By 2050 , this probability has risen to 20 $30 \%$.

A second bottleneck to the implementation of CCS is the effect of discounting the rise of the $\mathrm{CO}_{2}$ price curve. The present value of costs at the end of a project's lifetime is smaller compared to costs incurred at an early stage of the project. The $\mathrm{CO}_{2}$ emission cost is the only driver for CCS to be chosen as an economic option, and a high $\mathrm{CO}_{2}$ price at the end of a project may not compensate for the high upfront costs compared to a cheaper conventional fossil-fuel based technology. In a non-

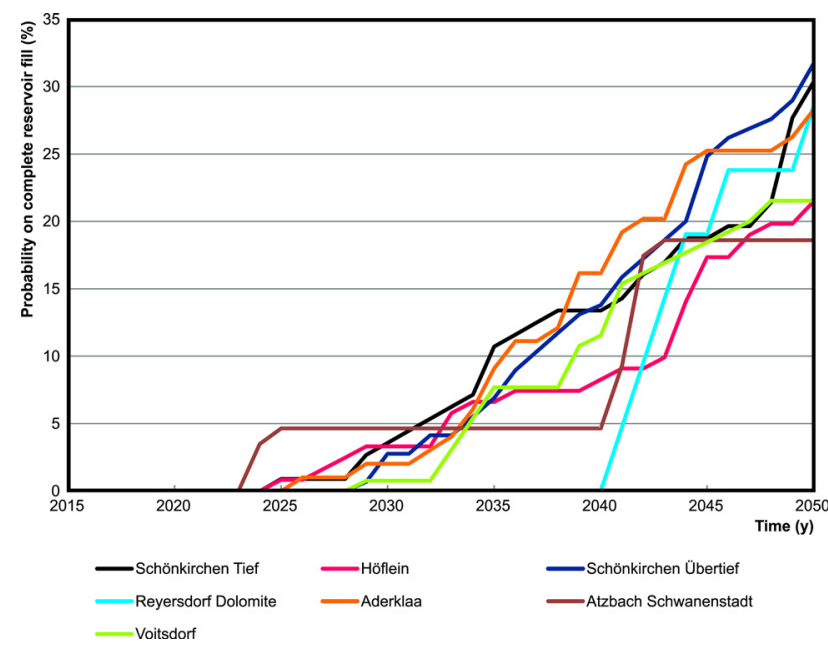

Figure 8. Probability that the reservoirs are filled completely by a certain moment in time. For some reservoirs, there is a small probability that the matched capacity reaches the practical capacity before 2025. By 2050, this probability lies around 20 to $30 \%$ for most reservoirs. 
subsidised situation, the same is true for renewable technology. Thus, conventional technologies are more likely to be chosen. A sufficiently high $\mathrm{CO}_{2}$ price early in the project lifetime is needed to justify the additional investment for capture and storage.

Possible solutions to these bottlenecks are to install capture on smaller sources, or to distribute the $\mathrm{CO}_{2}$ stream to multiple reservoirs. This should be addressed by future research. Another possible application for these smaller reservoirs is to fit CCS into other schemes, such as enhanced oil or gas recovery using anthropogenic $\mathrm{CO}_{2}$ as a solvent and propellant $\left(\mathrm{CO}_{2}\right.$-enhaced oil gas recovery, EOR/EGR). In Polak \& Grimstad (2009) this EGR possibility was investigated for the Atzbach-Schwanenstadt field. A matched capacity of $8.2 \mathrm{Mt}$ could be achievable using $\mathrm{CO}_{2}$ from a nearby paper mill and fertilizer plant. Though possible, an EGR project might be uneconomic due to a fast $\mathrm{CO}_{2}$ breakthrough and high $\mathrm{CO}_{2}$ reproduction. A sufficiently high EU ETS and gas price can offset the EGR cost, which might be subject to further study. The possibility of geothermal energy production by injecting $\mathrm{CO}_{2}$ in storage reservoirs, in $\mathrm{CO}_{2}$-enhanced geothermal systems ( $\mathrm{CO}_{2}$-EGS), is also being studied (e.g. Pruess, 2006; Randolph $\&$ Saar, 2011). These schemes provide a return that could make smaller scale projects profitable. In general though, capture of smaller amounts is more expensive, and the implication on the full CCS chain has to be studied.

The average yearly practical and matched capacity estimates by PSS III are 4.3 and $2.5 \mathrm{MtCO}_{2} / \mathrm{y}$ respectively for Austria. Considering the reported emissions from 2011 (6.2 $\mathrm{MtCO}_{2}$ for electricity and $11.3 \mathrm{MtCO}_{2}$ for iron \& steel production), about $14 \%$ of these emissions could be stored annually until 2050 . This means that the potential for reducing GHG emissions in Austria using CCS is not large, but still significant, even without exporting $\mathrm{CO}_{2}$ to neighbouring countries. When accounting for the whole uncertainty range, there is still a small probability that, under the simulated scenario, up to $10 \mathrm{MtCO}_{2}$ would be stored annually. As the assessed reservoirs are all (depleted) hydrocarbon reservoirs, the uncertainties associated with storing $\mathrm{CO}_{2}$ are in general smaller compared to other types of reservoirs. These reservoirs have contained oil or gas (in some cases with significant quantities of $\mathrm{CO}_{2}$ ) for long periods of time, which means that safe containment of injected $\mathrm{CO}_{2}$ is more likely.

At this moment CCS does not form part of Austria's climate policy, and storage of $\mathrm{CO}_{2}$ is not allowed except for research purposes (Shogenova et al., 2014). In the light of the latest UNFCCC Conference of Parties in Paris (COP21), where it was agreed to keep global temperature increase well below $2{ }^{\circ} \mathrm{C}$ above pre-industrial levels (UNFCCC, 2015), the global deployment of geological storage of $\mathrm{CO}_{2}$ as a mitigation technology becomes more urgent. The global target is very ambitious, and all available measures for emission reduction, including an increase in the rate of renewable energy production deployment, are necessary. Given that context, and with the potential for CCS as proven in this study, it may be necessary to revisit the ban on $\mathrm{CO}_{2}$ storage.

The results of this study show that the potential for geological storage of $\mathrm{CO}_{2}$ in Austria is relatively high, therefore a more indepth reservoir-specific assessment should be the next step. Also, production technologies with $\mathrm{CO}_{2}$ capture can be competitive with traditional technologies. Results can help optimal planning of climate and energy policy, and investments in CCS. This includes matching individual sources and sinks, but also assessing the CCS potential of regions and the whole country, as well as anticipating negotiations with other countries regarding cross-border transport of $\mathrm{CO}_{2}$. The actual implementation of CCS relies on an enabling policy framework in Austria, and a sufficiently stringent EU ETS system.

\section{Conclusions}

Potential geological reservoirs for storage of $\mathrm{CO}_{2}$ in Austria as a climate mitigation measure are assessed in this research using a methodology based on a techno-economic evaluation with PSS Explorer and the PSS III simulator. An assessment is made of the practical and matched capacity and of the reservoir development probability.

The results indicate a significant potential for $\mathrm{CO}_{2}$ geological storage in Austria. If it is allowed by policy, the probability of storage in Austria is almost $100 \%$. With a development probability of over $30 \%$ and the largest individual practical and matched capacity, the Schönkirchen Tief reservoir is ranked highest in our exploration priority list, and should be a primary target for further exploration if storage is desired. Reservoir selection of course depends on capacity and location match. Other reservoir development probabilities are around 20 to $25 \%$, except for the Reyersdorf Dolomite reservoir, which is not very favourable. The storage capacity of individual reservoirs seems to be a limiting factor for the implementation of capture technology. Possible solutions, which were not assessed in this research, are to install capture on smaller sources or to distribute the $\mathrm{CO}_{2}$ stream to multiple reservoirs. The use of anthropogenic $\mathrm{CO}_{2}$ for enhanced oil or gas recovery, or for geothermal energy production would also enable the use of smaller reservoirs.

Even without these technologies, CCS is expected to provide storage for, on average, $14 \%$ of all $\mathrm{CO}_{2}$ emissions from electricity and iron \& steel production, two of the most $\mathrm{CO}_{2}$ intensive industries in Austria, until 2050. A total average practical capacity of almost $120 \mathrm{Mt}$ is assessed to be available. Considering the techno-economic environment, including the European outlooks on the $\mathrm{CO}_{2}$ price, on average $40 \mathrm{MtCO}_{2}$ of matched capacity would be actually used if storage is allowed. It is important to consider the uncertainty ranges, as more storage capacity is potentially available. A first prerequisite for enabling storage, as well as other low- $\mathrm{CO}_{2}$ technologies, is a $\mathrm{CO}_{2}$ market price which rises quickly.

These results provide a first detailed assessment of the practical and matched capacity for $\mathrm{CO}_{2}$ storage in Austria, considering the current level of reservoir exploration, the techno-economic environment, and realistic uncertainties. It also enables exploration and infrastructure planning, and our results point out that CCS and domestic geological storage reservoirs in particular can provide a significant contribution to reducing the $\mathrm{CO}_{2}$ emissions of the country, even if Austrian policy and public opinion are currently largely opposed to storage.

\section{Acknowledgements}

The PSS simulator methodology was developed during the PSS-CCS projects funded by the Belgian Science Policy Office (contracts $\mathrm{SD} / \mathrm{CP} / 04 \mathrm{a} \& \mathrm{~b}$ and $\mathrm{SD} / \mathrm{CP} / 803$ ) and with internal funding at the Royal Belgian Institute of Natural Sciences Geological Survey of Belgium (RBINS-GSB). Part of this research was financed by the CGS Europe project exchange programme, funded by the European Union $7^{\text {th }}$ Framework Programme (contract 256725). The authors also wish to thank the experts who willingly provided their reservoir judgements, and Ed Garrett from the RBINS-GSB for providing critical comments. This manuscript benefited from the review comments of Jean-Marc Baele and Jort Rupert.

\section{References}

Bachu, S., Bonijoli, D., Bradshaw, J., Burruss, R., Holloway, S., Christensen, N.P. \& Mathiassen, O.M., 2007. $\mathrm{CO}_{2}$ storage capacity estimation: Methodology and gaps. International Journal on Greenhouse Gas Control, 1, 430-443.

BMLFUW, 2009. Erneuerbare Energie 2020: Potenziale und Verwendung in Österreich. Bundesministerium für Land- und Forstwirtschaft, Umwelt und Wasserwirtschaft, $48 \mathrm{p}$.

Brix, F. \& Schultz, O., 1993. Erdöl und Erdgas in Österreich.Vienna, Ferdinand Berger \& Söhne, 714 p.

Christensen, N.P. \& Holloway, S., 2004. Geological Storage of $\mathrm{CO}_{2}$ from Combustion of Fossil Fuel, EU FP5. The GESTCO project, Summary Report, 2nd ed. 32 p. http://www.geus.dk/program-areas/ energy/denmark/co2/GESTCO_summary_report_2ed.pdf.

Dixit, A. \& Pindyck, R., 1994. Investment under Uncertainty. Princeton, Princeton University Press, 488 p. 
Ebner F. \& Sachsenhofer R., 1991. Die Entwicklungsgeschichte des Steirischen Tertiärbeckens. Mitteilungen der Abteilung für Geologie und Paläontologie am Landesmuseum Joanneum, 49, 96 p.

E-PRTR, 2015. The European Pollutant Release and Transfer Register (E-PRTR), Member States reporting under Article 7 of Regulation (EC) No 166/2006, database v7. European Environment Agency.

European Commission, 2013. EU energy, transport and GHG emissions: trends to 2050. Reference scenario 2013. Luxembourg, Publications Office of the European Union 169 p.

European Council, 1993. 94/69/EC: Council Decision of 15 December 1993 concerning the conclusion of the United Nations Framework Convention on Climate Change. Official Journal L 033, 07/02/1994 P. 0011-0012.

European Parliament, 2009. Decision No 406/2009/EC of the European Parliament and of the Council of 23 April 2009 of the effort of Member States to reduce their greenhouse gas emissions to meet the Community's greenhouse gas emission reduction commitments up to 2020. Official Journal of the European Union L 140, 5.6.2009, 136-148.

Halland, E., Mujezinovic, J. \& Riis, F. (eds), 2014. CO Storage Atlas of the Norwegian Continental Shelf. Norwegian Petroleum Directorate, Stavanger, Norway, $163 \mathrm{p}$.

IEA, 2014. Energy Technology Perspectives 2014, Harnessing Electricity's Potential. OECD/IEA, Paris, 376 p.

IEA-ETSAP, 2013. International Energy Agency, Energy Technology Systems Analysis Program. http://www.iea-etsap.org.

IPCC, 2005. IPCC special report on carbon dioxide capture and storage. Prepared by Working Group III of the Intergovernmental Panel on Climate Change [Metz, B., Davidson, O., de Coninck, H.C., Loos, M., Meyer, L.A. (eds)]. Cambridge University Press, Cambridge, $442 \mathrm{p}$.

IPCC, 2014. Climate Change 2014: Mitigation of Climate Change. Contribution of Working Group III to the Fifth Assessment Report of the Intergovernmental Panel on Climate Change. [Edenhofer, O., Pichs-Madruga, R., Sokona, Y., Farahani, E., Kadner, S., Seyboth, K., Adler, A., Baum, I., Brunner, S., Eickemeier, P., Kriemann, B., Savolainen, J., Schlömer, S., von Stechow, C., Zwickel, T. \& Minx, J.C. (eds)], Cambridge University Press, Cambridge, 1435 p.

Keating, G.N., Middleton, R.S., Viswanathan, H.S., Stauffer, P.H. \& Pawar, R.J., 2011. How storage uncertainty will drive CCS infrastructure. Energy Procedia, 4, 2393-2400.

Keeling, R.F., Walker, S.J., Piper, S.C. \& Bollenbacher, A.F., 2014. Scripps $\mathrm{CO}_{2}$ Program. Scripps Institution of Oceanography, University of California. http://scrippsco2.ucsd.edu/data/atmospheric_co2.html.

Markowitz, H.M., 1987. Mean-Variance Analysis in Portfolio Choice and Capital Markets. Wiley, Milton Keynes, 379 p.

Middleton, R.S., Keating, G.N., Viswanathan, H.S., Stauffer, P.H. \& Pawar, R.J., 2012. Effects of geologic reservoir uncertainty on $\mathrm{CO}_{2}$ transport and storage infrastructure. International Journal of Greenhouse Gas Control, 8, 132-142.

Morgan, M.G. \& Keith, D.W., 2008. Improving the way we think about projecting future energy use and emissions of carbon dioxide. Climatic Change, 90, 189-215.

Neele, F., Mikunda, T., Seebregts, A., Santen, S., van der Burgt, A., Stiff, S. \& Hustad, C., 2013. A roadmap towards a European $\mathrm{CO}_{2}$ transport infrastructure. Energy Procedia, 37, 7774-7782.

Peresson, H. \& Decker, K., 1997. The Tertiary dynamics of the northern Eastern Alps (Austria): Changing palaeostresses in a collisional plate boundary. Tectonophysics, 272, 125-157.

Polak, S. \& Grimstad, A.-A., 2009. Reservoir simulation study of $\mathrm{CO}_{2}$ storage and $\mathrm{CO}_{2}$-EGR in the Atzbach-Schwanenstadt gas field in Austria. Energy Procedia, 1, 2961-2968.

Piessens, K., Welkenhuysen K., Laenen, B., Ferket, H., Nijs, W., Duerinck, J., Cochez, E., Mathieu, Ph., Valentiny, D., Baele, J.M., Dupont, N. \& Hendriks, Ch., 2012. Policy Support System for Carbon Capture and Storage and Collaboration between Belgiumthe Netherlands "PSS-CCS", Final report. Brussels, Belgian Science Policy, Research Programme Science for a Sustainable Development, 335 p. http://www.belspo.be/belspo/ssd/science/Reports/PSS-CCS_ FinRep_AD.2.pdf.

Prey, S., 1980. Die Geologie Österreichs in ihrem heutigen geodynamischen Entwicklungsstand sowie die geologischen Bauteile und ihre Zusammenhänge. In: Oberhauser, R. (ed.), Der geologische Aufbau Österreichs. Geologische Bundesanstalt \& Springer-Verlag, Vienna, New York, 79-118.

Pruess, K., 2006. Enhanced geothermal systems (EGS) using $\mathrm{CO}_{2}$ as a working fluid - A novel approach for generating renewable energy with simultaneous sequestration of carbon. Geothermics, 35, 351367.

Randolph, J.B. \& Saar, M.O., 2011. Coupling carbon dioxide sequestration with geothermal energy capture in naturally permeable, porous geologic formations: Implications for $\mathrm{CO}_{2}$ sequestration. Energy Procedia, 4, 2206-2213.
Rupp C., Linner M. \& Mandl G.W., 2011. Erläuterungen geologische Karte von Oberösterreich 1:200 000. Geologische Bundesanstalt, Vienna.

Scharf, C. \& Clemens, T., 2006. $\mathrm{CO}_{2}$-sequestration potential in Austrian oil and gas fields (SPE100176). In SPE EUROPEC/EAGE Annual Conference and Exhibition, 12-15 June 2006, Vienna, Austria.

Seifert, P., 1992. Palinspastic reconstruction of the easternmost Alps between Upper Eocene and Miocene. Geologica Carpathica, 43, 327-331.

Shogenova, A., Piessens, K., Holloway, S., Bentham, M., Martínez, R., Flornes, K.M., Poulsen, N.E., Wójcicki, A., Sliaupa, S., Kucharič, Dudu, A., Persoglia, S., Hladik, V., Saftic, B., Kvassnes, A., Shogenov, K., Suárez, I., Sava, C., Anghel, S. \& Chikkatur, A., 2014. Implementation of the EU CCS Directive in Europe: results and development in 2013. Energy Procedia, 63, 6662-6670.

Statistics Austria, 2009. Energy balances for Austria and the Laender of Austria. https://www.statistik.at/web_en/statistics/energy_ environment/energy/energy_balances/index.html.

UNFCCC, 2006. Austria's Initial Report under the Kyoto Protocol. Federal Ministry of Agriculture and Forestry, Environment and Water Management. Vienna, Austria. http://unfccc.int/files/national_ reports/initial_reports_under_the_kyoto_protocol/application/pdf/ at-initial-report-200611-corr.pdf.

UNFCCC, 2015. Adoption of the Paris Agreement. United Nations, Framework Convention on Climate Change, Conference of the Parties, FCCC/CP/2015/L.9/Rev.1, 32 p. https://unfecc.int/resource/ docs/2015/cop21/eng/109r01.pdf.

Umweltbundesamt Österreich, 2014a. Austria's National Inventory Report 2014. Submission under the United Nations Framework Convention on Climate Change and the Kyoto Protocol. National inventory report 2013. Vienna, Report REP-0475, $553 \mathrm{p}$.

Umweltbundesamt Österreich, 2014b. Klimaschutzbericht 2014. Vienna, Report REP-0491, 170 p.

Vangkilde-Pedersen, T., Allier, D., Anghel, S., Bossie-Cordreanu, D., Car, M., Donda, F. et al., 2009. Assessing European Capacity for Geological Storage of Carbon Dioxide. EU GeoCapacity, D16 WP2 Report, Project no. SES6-518318, 166 p. http://www.geology.cz/ geocapacity/publications/D16 WP2 Report storage capacity-red.pdf.

Welkenhuysen, K., Ramírez, A., Swennen, R. \& Piessens, K., 2013. Strategy for ranking potential $\mathrm{CO}_{2}$ storage reservoirs: a case study for Belgium. International Journal of Greenhouse Gas Control, 17, 431-449.

Wessely, G., 2006. Geologie der Österreichischen Bundesländer, Niederösterreich. Geologische Bundesanstalt, Vienna, 416 p.

ZEP, 2011. The Costs of CO 2 Storage. European Technology Platform for Zero Emission Fossil Fuel Power Plants, Brussels, 42 p. http:// www.zeroemissionsplatform.eu/downloads/814.html. 


\section{Appendix}
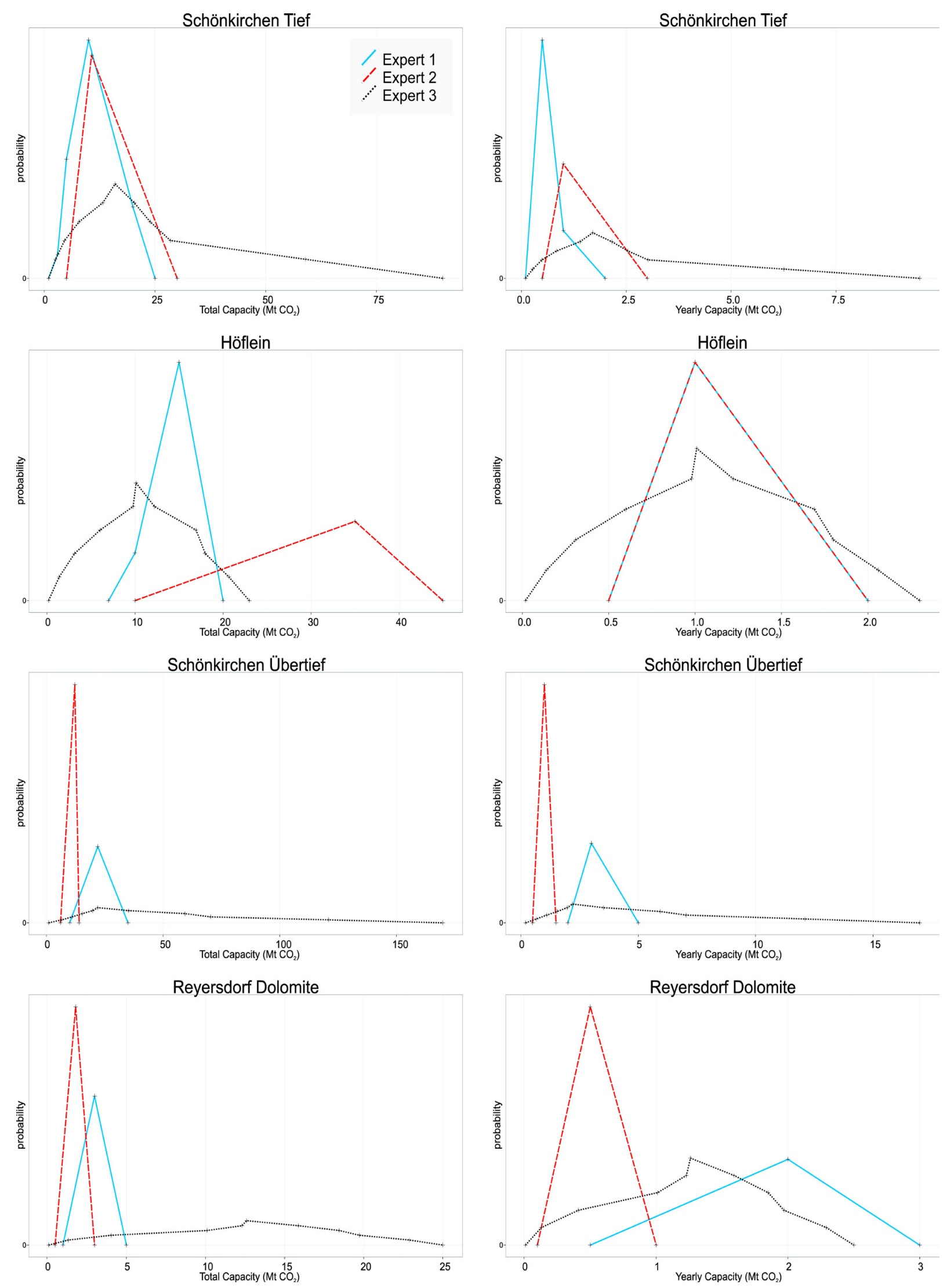

Figure 9. Expert judgements for each reservoir as total capacity and injectivity probability density functions, and the probability on reservoir failure. 
Aderklaa

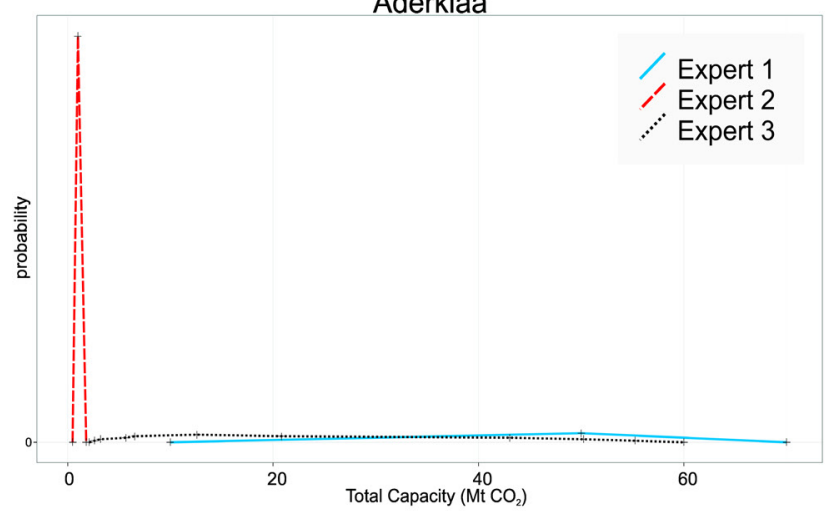

Atzbach Schwanenstadt

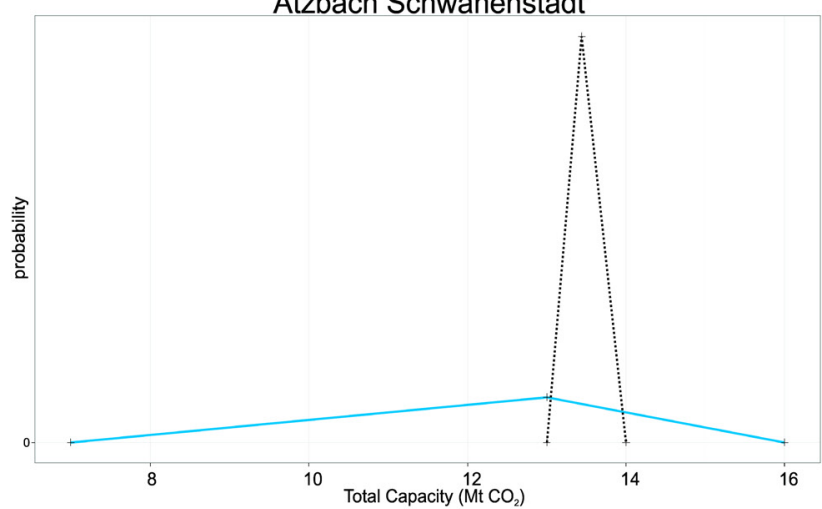

Voitsdorf

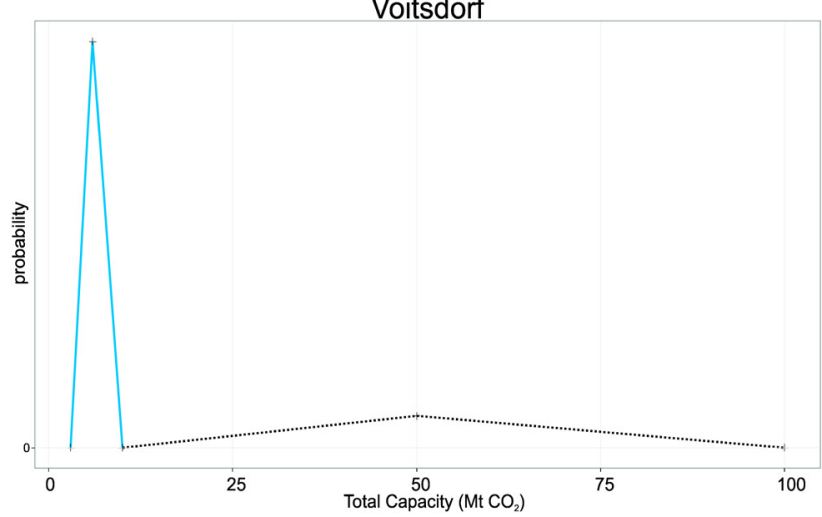

Aderklaa

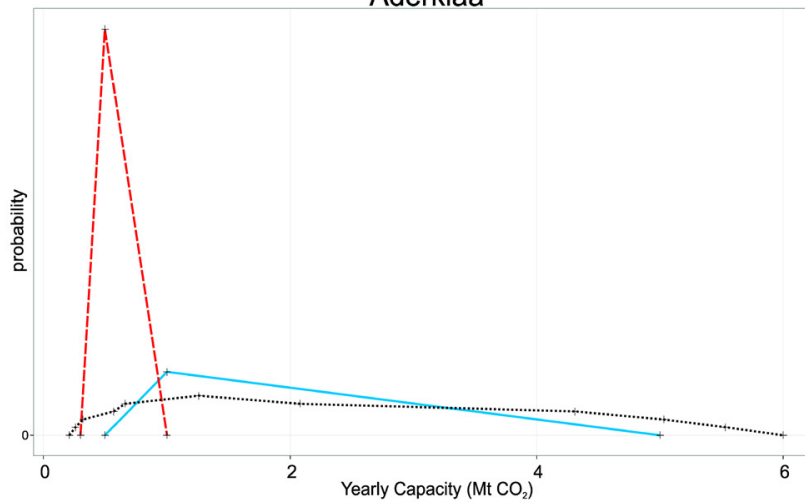

Atzbach Schwanenstadt

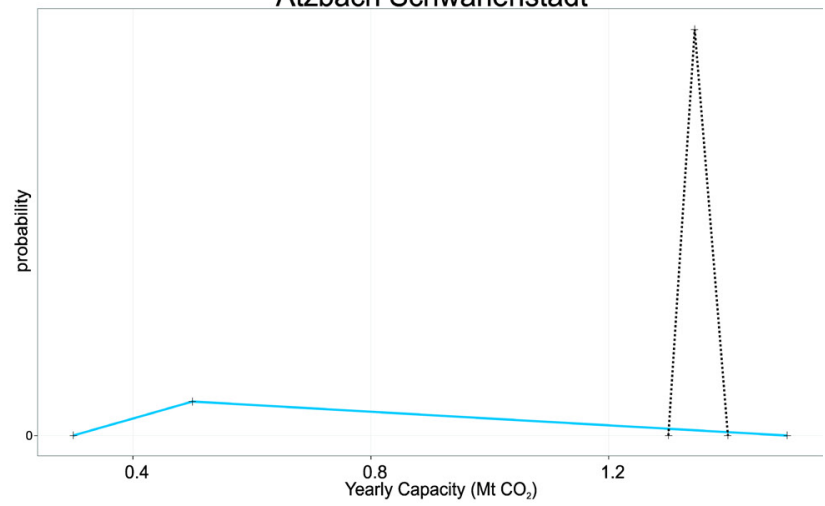

Voitsdorf

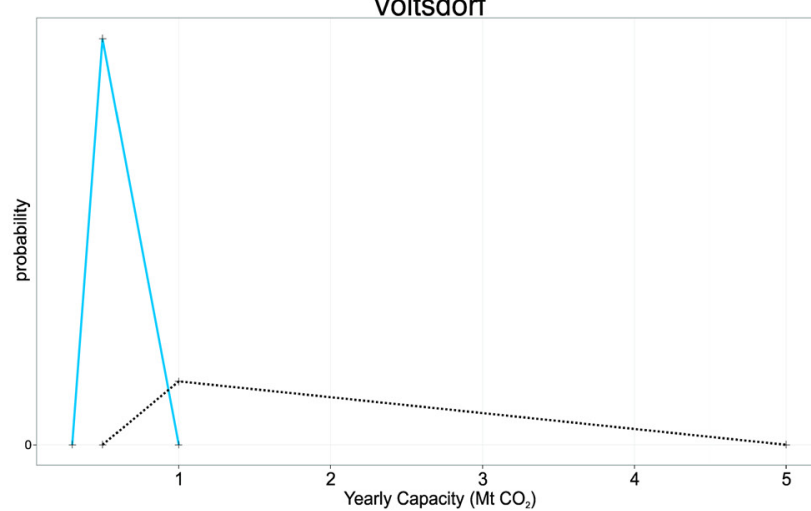

Reservoir failure probability

\begin{tabular}{lrrr}
\hline Reservoir & Expert 1 & Expert 2 & Expert 3 \\
\hline Schönkirchen Tief & 0.02 & 0 & 0.3 \\
\hline Höflein & 0.01 & 0.3 & 0.2 \\
\hline Schönkirchen übertief & 0.01 & 0.2 & 0.2 \\
\hline Reyersdorf Dolomite & 0.02 & 0.7 & 0.2 \\
\hline Aderklaa & 0.05 & 0 & 0.5 \\
\hline Atzbach-Schwanenstadt & 0.1 & - & 0.5 \\
\hline Voitsdorf & 0.12 & - & 0.2
\end{tabular}

Figure 9 continued. Expert 2 chose not to evaluate the Atzbach-Schanenstadt and Voitsdorf reservoirs. 

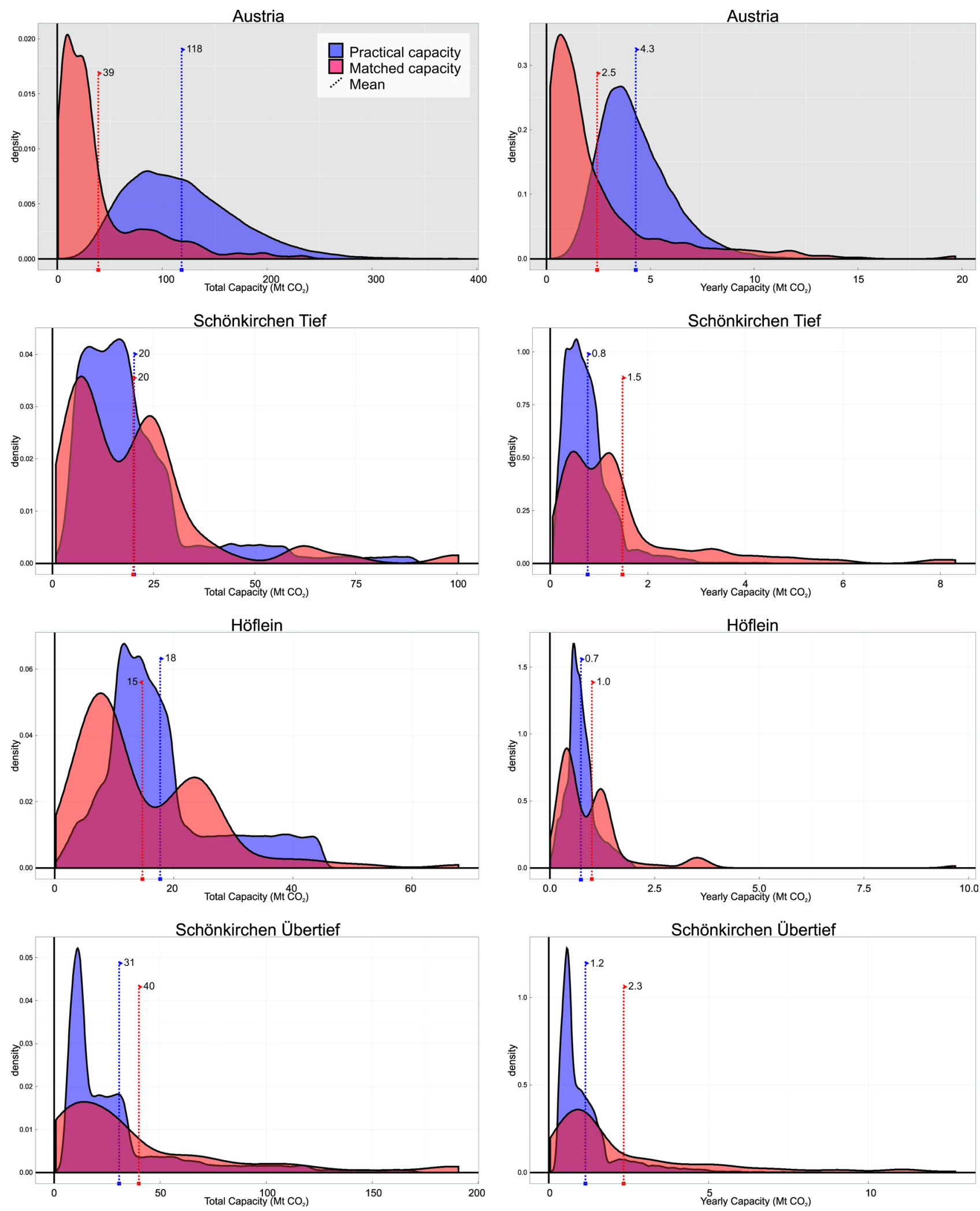

Figure 10. Practical (blue) and matched (red) capacity probability density functions, as calculated by PSS Explorer and PSS III. Average values are indicated by the dashed lines. A kernel density estimation with a normal distribution is used to construct these PDF's from datasets with a finite population. 

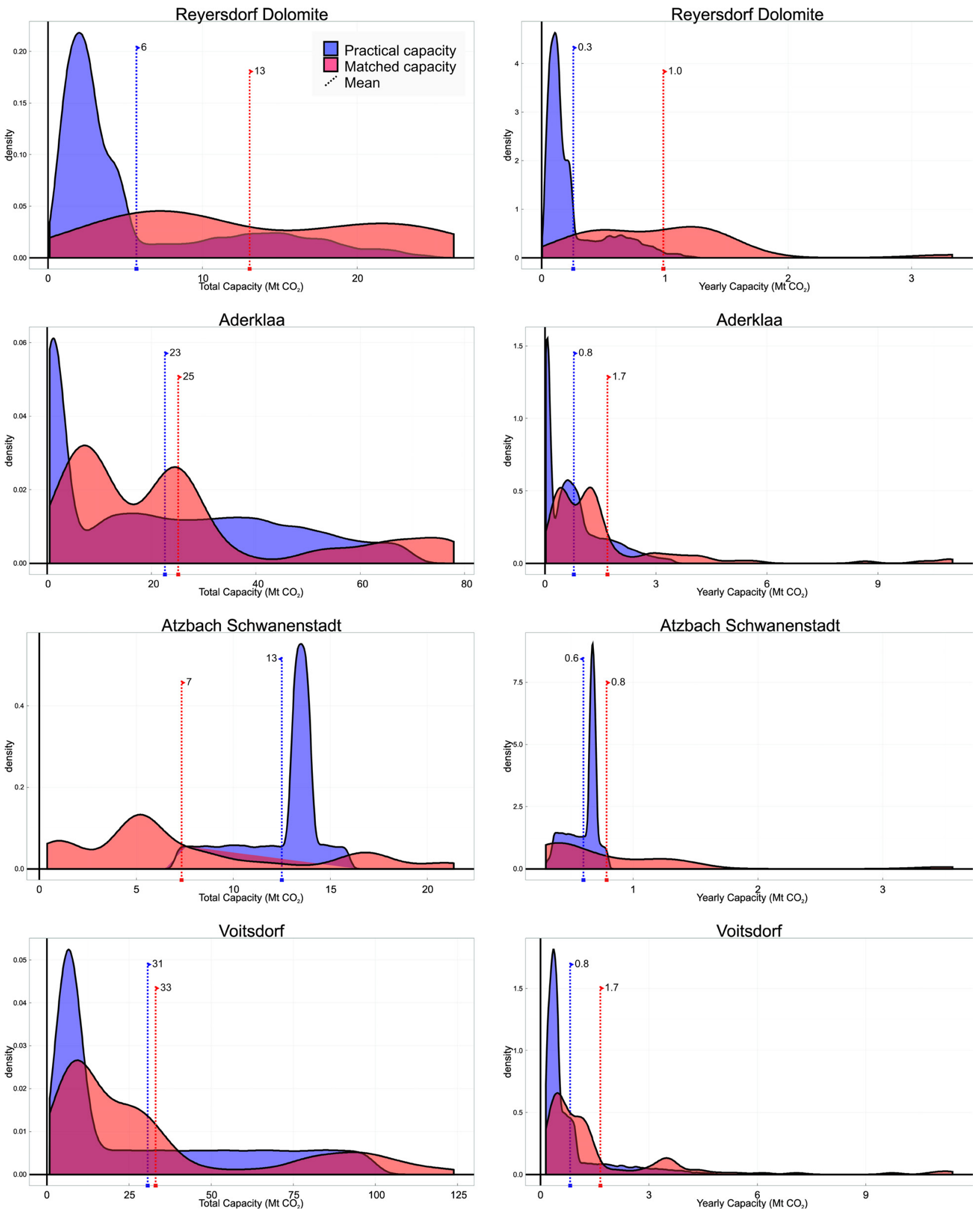

Figure 10 continued. 